\title{
Explaining Nurses' Perception of the Causes of Ageism in Hospital Settings
}

\author{
Saeid Mehri ${ }^{1}$, Mohammad Ali Hosseini ${ }^{2^{\star}}$, Farahnaz Mohammadi Shahbelaghi ${ }^{3}$, Masoud Fallahi-Khoshknab ${ }^{2}$, \\ Saeed Akbari Zardkhaneh ${ }^{4}$
}

\author{
${ }^{1}$ Department of nursing, PhD candidate, University of Social Welfare and Rehabilitation, Tehran, IRAN \\ ${ }^{2}$ Department of nursing, University of Social Welfare and Rehabilitation Sciences, Tehran, IRAN \\ ${ }^{3}$ Department of nursing, Iranian Research Center of Aging, University of Social Welfare and Rehabilitation Sciences, Tehran, IRAN \\ ${ }^{4}$ Department of psychology, Shahid Beheshti University, Tehran, IRAN \\ *Corresponding Author: mahmaimy2020@gmail.com
}

Citation: Mehri S, Hosseini MA, Shahbelaghi FM, Fallahi-Khoshknab M, Zardkhaneh SA. Explaining Nurses' Perception of the Causes of Ageism in Hospital Settings. Electron J Gen Med. 2020;17(5):em218. https://doi.org/10.29333/ejgm/7881

\section{ARTICLE INFO \\ Received: 1 Oct. 2019}

Accepted: 13 Jan. 2020

\begin{abstract}
Objective: Given the aging population increase, providing quality care to the elderly is one of the major challenges of health care systems. The purpose of the present study is to explain the perception of nurses about the causes of ageism in providing hospital care to the elderly referred to hospital settings in the city of Tehran.

Methods: The study utilized a qualitative design with individual interviews and with Conventional Content Analysis Approach. In this qualitative study, participants were selected through a purposive sampling method. Semi-structured and in-depth interviews with health care providers were conducted in the city of Tehran in 2018 guided by data saturation. All interviews were recorded and implemented and then analyzed by Graneheim and Lundman method.
\end{abstract}

Results: Analysis of data extracted from interviews divided into five main categories "patient related factors", "care provider related factors", "factors related to care provider system", "socio-economic factors" and " family related factors", each of which was under positive and negative subcategories.

Conclusion: The results of this study showed that there is a negative discrimination in the provision of nursing care services in the hospital settings, which is not a good predictor of good health care for the elderly. Therefore, it is recommended that culture-building, training and awareness-raising and proper planning be carried out in care settings to combat ageism.

Keywords: ageism, hospital, care, elderly, qualitative analysis, causes

\section{INTRODUCTION}

In the twenty-first century, one of the major challenges of care systems is the provision of quality services to elderly people (1). More than 36.5 million people, or about oneseventh of Americans (14\%), are 65 years of age or elderly (2). In Iran, which is a developing country, based on the 2016 census, Iran's Statistics Center accounts for 1.6 million people from Iran's population of 80 million people who are aged 65 and over; and it is predicted that the population over the age of 60 will be more than $10 \%$ in $2021(3,4)$.

According to the World Health Organization, 23.1 percent of the global burden of disease is undergone by people over the age of $60(5,6)$. On the other hand $35 \%$ of the elderly are admitted to hospitals (2). Discrimination, prejudice and stereotyped behaviors towards the elderly are potential barriers that affect the quality and quantity of care provided and the outcome of nursing care (5). Furthermore studies based on clinical decision making hypotheses and the points of view in the elderly patients concerning the discrimination in providing care in most diseases, including cardiovascular (7), cancer (8), and stroke treatment (9).

In 1969, Butler first defined Ageism as "prejudice by one age group towards other age groups" (10). Since then, much research has been carried out on this concept in different settings and changes have been made to its definition (11). São José and Amado in 2017 introduced ageism in this way "Ageism is defined as negative or positive stereotypes, prejudice and/or discrimination against (or to the advantage of) us on the basis of our chronological age or on the basis of a perception of us as being "old," "too old," "young" or "too young." Ageism can be self-directed or other-directed, implicit or explicit and can be expressed on a micro, meso or macro-level.” (12).

While effort to train human resources for elderly care has improved, there are still some shortcomings in their care. Inappropriate hospital care, lead to early loss of independence, increased inability and death in the elderly who still have productive capacity and lived healthy lives. In this regard, several studies have linked ageism with poor quality care (1315). Bonnie et al. (2003) reported that one of the predictions of mental abuse in care units is the negative attitude of nurses 
towards the elderly (16). Also, some studies have shown that although people have a positive attitude towards the elderly, their behavior towards the elderly patients was negative $(5,17,18)$.

The root of ageism is based on research conducted in general from individuals to society, culture to the economy, as well as government policies, and accordingly categorizes the causes of discrimination into three main categories of personal resources, socio-economic effects, and cultural resources (19).

Ageism reaches a point where care for elder persons has a tendency to be devalued regardless of setting, with this devaluation specifically seen in care settings, compounded by poor social status and low compensation. Ageism in health care and in the nursing profession creates oppression for old patients, resulting in harmful effects (20). Ageism in care settings leads to a reduction in communication and lack of communication to facilitate understanding in the elderly reduces their awareness (21) and, reduces screening (22). It also reduces some preventive health services (23), shortages of prescriptions (24) and decreases prescribing experiments and treatment for the elderly $(25,26)$.

Considering the consequences of ageism, especially in hospital settings and the lack of relative research, researchers decided to study ageism in Iranian elderly patients using nursing experience with a qualitative study. In this study, considering the complex structure of ageism, the aim is to explain the effective factors of ageism at the individual level and in the hospital settings.

\section{MATERIALS AND METHODS}

This research was a qualitative study carried out in 2018, by qualitative conventional content analysis method (27). The present study field was located in Tehran educational and therapeutic hospitals.

The number of participants in this study were 14 people in total including 10 clinical nurses, 3 head nurses and one educational supervisor. In terms of gender there were 5 women and 9 men with work experience of at least 4 years to a maximum of 21 years and a minimum age of 25 and a maximum of 52 years. Sampling was done based on the purposive selection of the participants. Participants were selected from among care providers in hospitals. Attempts were made to select contributors who, in addition to being experienced enough, would be willing to collaborate and participate in research and have good speaking skills. For more information further interviews were arranged. Finally, interviews were conducted with 14 hospital care providers until data saturation. Participants were selected with maximum diversity (in terms of age, work experience, education). In the present study, hospital care providers were nurses who had the most time to care for the elderly, and the participants chosen were experienced and had two years of work experience.

The main method of data collection was semi-structured and in-depth interviews using open questions. The interviews were conducted individually and in a quiet environment that was selected by the participants. The interview began with the open question "What do you have in mind when you take care of an elderly person"? How did you feel about taking care of young and old patients in the hospital settings?" Then, given the responses and clarification and the depth of the conversation, there were other exploratory questions to follow asking for more explanation? Questions like 'what do you mean exactly? The duration of interviews varied from 45 to 70 minutes. All interviews were recorded, implemented, and immediately typed word by word.

In order to analyze the data, the researcher listened to interviews several times and reviewed them repeatedly for immersion in the text information typed. Data analysis was performed simultaneously with their collection and Constant comparative analysis. The approach of Grenhaeim and Lundman (2004) was used in order to analyze the data in line with the purpose of the research. The steps of this approach include the researcher's acquaintance with the data, production of primary code data, the search for themes, review of the various extracted codes in the previous steps, review of the themes, and comparing them again with the data to ensure their accuracy, defining and naming the themes and preparation for the final report (28).

The proposed Guba (1981) criteria included credibility, conformability, dependability, and transferability and was used to ensure the accuracy and reliability of the data and findings (29). One of the most important methods for establishing credibility is long-term conflict with the subject of the research, with the researcher trying to spend more time in the hospital settings. Meanwhile, for data availability, before the interview, the researcher met the participants several times in order to gain their trust and create a good relationship with the participant and atmosphere suitable for conducting an indepth interview. Also, the findings were reviewed by contributors. Parts of the text of the interview and the codes were returned to their comments on the validity of the materials approved for these findings.

The findings were reviewed by the supervisors and the research team to confirm and validate the findings. For this purpose, parts of the interview text, along with the relevant codes and classes, were evaluated by the research team that review the flow of analysis and review their validity. Also, data collection and analysis were performed simultaneously for data stabilization. The researcher carefully recorded and documented the process and the research process to validate and audit the research so that others can follow the research. For transferability and proportionality, findings were shared with a number of hospital care providers who were not involved in the research to confirm the appropriateness of the findings, and the way to achieve the results was accurately outlined. Also, the use of sampling technique with maximum diversity that contributes transferability of findings to others is considered in this study.

The present research is part of the Ph.D. Nursing Thesis, which has been approved by the Ethics Committee of the University of Social Welfare and Rehabilitation Sciences University under the code IR.USWR.REC.2017.263. The sampling began after obtaining the necessary permission. Before the interview, the purpose of the research, the method of work, the confidentiality of information and the right to participate in or leave the study were explained to the participants and their informed consent was obtained. The interview time was adjusted in co-ordination and with the participant's request, so that it did not interfere with their daily schedules. 
Table 1. Discrimination in the provision of care for the elderly in hospital settings

\begin{tabular}{|c|c|c|}
\hline Main category & Subcategory & Codes \\
\hline \multirow[t]{2}{*}{$\begin{array}{l}\text { Patient Related } \\
\text { Factors }\end{array}$} & Positive & $\begin{array}{l}\text { Self-care ability, low workload, lack of dependence on others, good relationship and collaboration with } \\
\text { caregivers, knowledge about disease, alertness of the elderly, male }\end{array}$ \\
\hline & Negative & $\begin{array}{l}\text { Intolerance, loss of performance, lack of mobility, history of hospitalization, psychological problems, nutritional } \\
\text { problems, high workload, need for comprehensive care, dependency, early suffering, desire for early discharge, } \\
\text { hearing and vision impairments, swallowing and digestive problems, lack of cooperation, misbehavior, } \\
\text { aggression, inability to provide biographies, cognitive impairments, health problems, severity of illness, low } \\
\text { self-care, need special care, female }\end{array}$ \\
\hline \multirow[t]{2}{*}{$\begin{array}{l}\text { Caregiver } \\
\text { related factors }\end{array}$} & Positive & $\begin{array}{l}\text { positive attitude to old age, care based on justice, caring when needed, sense of responsibility towards the } \\
\text { elderly, enjoy elderly care, making conversation with the elderly }\end{array}$ \\
\hline & Negative & $\begin{array}{l}\text { Hatred of the elderly, belief in the lack of improvement in the elderly, negative attitude towards elderly, age is } \\
\text { the criterion of care, aging is a disability and dependence, neglect of the elderly, lack of attention to elderly and } \\
\text { adolescent care, fatigue, second priority care elderly, lack of attention to the elderly vital care, making decisions } \\
\text { for the elderly, labeling the elderly, failure to pay attention to the complications of injected drugs, lack of } \\
\text { attention to patient complaints, incomplete assessment of the patient, lack of patient privacy, incomplete } \\
\text { treatment period in the elderly, low awareness of some interventions for elderly, quick decision making for the } \\
\text { elderly, lack of knowledge about the elderly }\end{array}$ \\
\hline \multirow[t]{2}{*}{$\begin{array}{l}\text { Care provider } \\
\text { system factors }\end{array}$} & Positive & $\begin{array}{l}\text { Personnel training on aging, supervision of personnel performance, elderly nurse recruiting, elderly care for } \\
\text { experienced staff, Monitoring of the elderly people's shortcomings }\end{array}$ \\
\hline & Negative & $\begin{array}{l}\text { No priority for the elderly, lack of management, lack of facilities needed for elderly care, staff shortages, lot of } \\
\text { workload in department, neglecting elderly care, poor patients distribution, poor supervision, lack of elderly } \\
\text { care culture, limiting the services offered to elderly, profitability from the elderly }\end{array}$ \\
\hline \multirow{2}{*}{$\begin{array}{l}\text { Socio- } \\
\text { economic } \\
\text { factors }\end{array}$} & Positive & $\begin{array}{l}\text { High socio-economic status, the elderly experience, positive beliefs towards the elderly, social and political } \\
\text { support }\end{array}$ \\
\hline & Negative & $\begin{array}{l}\text { Low socioeconomic status, increasing number of hospitalized elderly, negative beliefs towards the elderly, } \\
\text { costly care for elderly, lack of social and insurance support, undervalued elderly care in the community, the } \\
\text { normalization of death of the elderly, the importance of care of elderly in the hospital, the chances of survival } \\
\text { are the criterion for receiving hospital care, inappropriate policy, ineffective elderly care }\end{array}$ \\
\hline \multirow[t]{2}{*}{$\begin{array}{l}\text { Family related } \\
\text { factors }\end{array}$} & Positive & $\begin{array}{l}\text { All-round support for elderly, good communication and co-operation with caregivers, respect and value to the } \\
\text { elderly }\end{array}$ \\
\hline & Negative & $\begin{array}{l}\text { Neglecting elderly, preferring death of the elderly to life, making decisions instead of patient, rejection by the } \\
\text { family, inadequate elderly care }\end{array}$ \\
\hline
\end{tabular}

\section{RESULTS}

In the present study, 1450, the initial code was derived from the fruitful and profound descriptions of the participants. The initial codes were sorted according to similarity and relevance after several reviews and summarizations. Considering the approach of Iverson 2009 (30) and São José 2017 (12), ageism was considered in both positive and negative sections. In the process of data analysis, the five main categories of "patient related factors", "care provides related factors", "factors related to the care provider system", "socio-economic factors" and "family related factors", each of which positive and negative categories transpired, which have been presented in Table 1.

\section{Category 1: Patient related Factors}

Physical, psycho-behavioral, health, disease conditions, and care needs of the elderly are factors, according to the beliefs of the participants that can positively and negatively affect care delivery. Some parts of the participants' comments are as follows:

\footnotetext{
"The elderly do not cooperate and their illnesses are complicated and care is also difficult and many are multifunctional; it's as if you take care of a few patients. Some colleagues sometimes say they do not like to take care of the elderly but others, although they do not like it, do not actually say it, but there are signs of dislike in their comments, including saying things like 'he is old, what can I do to him?" (Female nurse with 11 years' experience)
}

\section{Another contributor stated that}

\begin{abstract}
"a young person can take care of themself and can easily see to his own affairs and the personnel will give him tasks to do and he can complete them, so everyone likes to care for this patient but the elderly, on the contrary, need a lot of care and all their daily tasks must be done for them." (A male nurse with 3 years of experience).
\end{abstract}

\section{Category 2: Caregiver related Factors}

In some cases, the root of discrimination in care provided to the elderly depends on the personality and other factors related to the caregiver. In these cases, the participants stated:

\begin{abstract}
"Some colleagues who themselves have moral issues and may not prescribe the medication of elderly patients and keep that secret from everyone because it has consequences." (A male nurse with 3 years of experience)
\end{abstract}

An emergency worker (a man with 15 years of work experience) says:

\footnotetext{
"One day the code was announced, I went back to the patient as is required. I saw one of my colleagues who had just come on their shift, they said where are you going? I said 'didn't you hear they announced the code. They said leave it, the patient is $\mathbf{9 0}$ years old, what else do you expect, leave them be. God knows how long it had been, since the code has been announced, and to cut a long story short, they delayed seeing to the patient and the patient died."
} 


\section{Category 3: Factors related to the Care Provider System}

The health care provider system, according to participants' comments in this research, is effective in providing care to the benefit of the elderly, not just some of the experiences contributed by the participants below:

Educational supervisor (man with 21 years of experience) says:

\begin{abstract}
"The system itself is causing the problems, there are personnel who love their job because working with the elderly is a very rewarding job. Some staff say that what's the point in spending time and money on this elderly patient? Of course, the system, the family, and even the personnel do not say this publicly, but it still exists, they say it's useless wasting energy on the elderly'
\end{abstract}

\section{Category 4: Socio-economic Factors}

Hospital caretakers in this study considered the economic and social factors as influential factors in the discrimination against or to the benefit of the elderly patients in hospital care. Below are some of the statements by contributors:

The department director with 20 years of experience said.

\begin{abstract}
"The social and economic situation of the elderly patient is very important, the fact is that no one likes to go near them. For example, in the case of an elderly addict, it is said say that he does not have mercy on himself, so why should I bother myself and care about him. If you don't care about yourself and how old you are, why should we?"
\end{abstract}

\section{Category 5: Family related Factors}

The importance and value of the elderly family to the elderly patients or vice versa can affect the quality and quantity of care provided to the elderly in terms of contributors to this research:

\begin{abstract}
"In some cases, there is the issue of dealing with cares for example the patient's relatives who do not respect the nurses, in turn, make the nurses neglect the patient. If the care provider, the conscientious service provider has pride in himself, that service will be enhanced and strengthened. We see sometimes, that the family of the patient themselves like their relative to die and are not bothered very much. It's affecting our performance." (A male nurse with 14 years of experience).
\end{abstract}

\section{DISCUSSION}

The aim of this study was to explain the perceptions of nurses about the causes of ageism in hospital settings. Many of the factors associated with discrimination in the provision of hospital care for the elderly are probably due to attitudes and behavior of those in the health system, hospital caregivers and even the patients themselves and the family of the elderly patient being referred to the hospital. These factors can play an important role in elderly care and can affect the quality of care provided to the elderly and may endanger the life and health of the elderly $(31,32)$.
The findings of the present study reveal discrimination in providing care to the elderly in five categories, including factors related to patients, caregivers, the care provider system, socioeconomic, and family background. Some of these factors have a positive effect, and some that carry more weight in this study have a negative effect on receiving and providing care to the elderly.

According to participant's comments in the present study, self-care ability, communication and collaboration with hospital caregivers, elderly patient's awareness about their illness are factors that make caregivers more caring towards the elderly. In contrast the lack of elderly collaboration, loss of performance, the need for universal care of the elderly, cognitive disorders and non-compliance with health issues makes health care providers less interested in care and admission of the elderly. But if there is coercion in providing care, poor quality care is provided. The findings of this study can be compared with individual sources of ageism (19), as well as a self-directed discriminatory type of discrimination, according to Bodner (33) and Ayalon (34) study.

According to participant's comments in the present study, a Positive attitude towards the elderly, makes the care provided to the elderly patients in compliance to their needs. The quality of care will be improved and the elderly patients satisfaction with the care provided will increase. Otherwise, if hospital care providers believe there will be no significant improvement in the elderly patients health in the hospital, these factors, along with the high level of work-related fatigue and lack of awareness of caregivers about elderly considerations, it will lead to health care providers taking care of the elderly as their second priority which reduces the quality of care and neglects the care of the elderly patients in hospital care. These factors are rooted in the beliefs and knowledge of caregivers about the elderly and lead to subsequent caring behavior. The findings of the present study, with the division of the study of Iverson (30) and São José (12), are consistent with ageism. This finding is consistent with studies that have been conducted in the field of a positive attitude of the elderly in admission and care, and increases the awareness of caregivers about aging and better care $(11,35-37)$.

The elderly care provider system can also be effective in providing care to the elderly based on the views of the hospital caregivers in the present study. Participants in this study stated that: If the system provides care for personnel and trains them in regard to the elderly, with adequate supervision and spends time and money on promoting care of elderly patients and turning out experienced caregivers then care will improve. Otherwise, care for this age group will be marginalized and the quality of care will deteriorate. This finding corroborates the findings of the Pekince study which showed that experienced people provide better care (38), as well as Liu's finding (2) in which work experience with the elderly with a positive attitude, creates a management system in the hospital which will reduce the discrimination present in providing care for the elderly alongside good planning.

Also, the study participants stated that due to the increase in the number of elderly people in the country, the rate of return of the elderly to the hospital has also increased, and as a result of which the social and economic condition of the elderly is not explicit and obvious at present. In contrast to the low socioeconomic situation of the elderly, the negative attitude of the community towards the elderly, the care of elderly with unnecessary cost to the community and, thus, low 
quality elderly care, promotes the importance of better caring for the elderly or elderly patient mortality will become commonplace in the hospital. Health care providers should provide the patient with a better chance of survival. This finding is also consistent with the socio-economic causes of age discrimination, which plays the most important role in the advancement of discrimination (19).

One of the most important findings of the present study was that the patients' family, according to participants comments, had the most important effect on the care of the elderly, and if the family does not protect their elderly relatives, it will have a direct effect on them. The factors mentioned above are in line with the study of São José, and are indicative of other-directed ageism (12).

The main advantage of the present study is that various studies show ageism in clinical settings as well as negative attitudes of health care providers towards the elderly patients However, the exact causes of this discrimination in the provision of elderly care in such settings is still not clear. Therefore, the present study was a step in the clarification of these factors $(12,31)$.

Current qualitative research has been done based on perceptions and views of employed nurses, therefore, like other qualitative studies, consideration should be given to caution in generalizability. This means that the classification of the present research in the studied population will be used and its application in different societies requires more studies.

\section{CONCLUSION}

Regarding the results of present research, discrimination in providing hospital care to the elderly is one of the challenges of clinical settings. In addition to the patient and its associated factors, the care provider system, caregiver and also the elderly patients' family are effective in the discrimination against or to the benefit of the elderly. Negative attitudes to old age due to the increasing growth of the aging population and an increase in the referral of elderly patients to the hospital does not promise good care for the elderly. Therefore, it is recommended that health policy makers, managers and providers of health care should be employed in order to strengthen the positive factors and combat the negative factors that lead to discrimination against the elderly.

\section{ACKNOWLEDGEMENTS}

This article is part of the Ph.D. Nursing Thesis entitled "Design and validation of ageism tool in hospital caregivers", University of Social Welfare and Rehabilitation Sciences of Tehran. Researchers need to acknowledge and appreciate all the participants in this research.

\section{Conflict of Interest}

The author(s) declared no potential conflicts of interest with respect to the research, authorship, and/or publication of this article.

\section{Funding}

The author(s) received no financial support for the research, authorship and/or publication of this article.

\section{REFERENCES}

1. Rejeh N, Heravi-Karimooi M, Vaismoradi M. Iranian nursing students' perspectives regarding caring for elderly patients. Nursing \& health sciences. 2011;13(2):118-25. https://doi.org/10.1111/j.1442-2018.2011.00588.x PMid:21401841

2. Lui NL, Wong CH. Junior doctors' attitudes towards older adults and its correlates in a tertiary-care public hospital. Annals Academy of Medicine Singapore. 2009;38(2):125.

3. Statistical center of Iran. Available at: https://www.amar.org.ir

4. Sum S, Emamian S, Sefidchian A. Aging educational program to reduce ageism: intergenerational approach. Elderly Health Journal. 2016;2(1):33-8.

5. Ayalon L, Tesch-Römer C. Contemporary Perspectives on Ageism: Springer; 2018. https://doi.org/10.1007/978-3-31973820-8 PMid:29890938 PMCid:PMC5996519

6. Thiem $U$, Theile $G$, Junius-Walker $U$, Holt $S$, Thürmann $P$, Hinrichs T, et al. Prerequisites for a new health care model for elderly people with multimorbidity. Zeitschrift für Gerontologie und Geriatrie. 2011;44(2):115-20. https://doi.org/10.1007/s00391-010-0156-z PMid:21161244

7. Bowling A. Ageism in cardiology. BMJ: British Medical Journal. 1999;319(7221):1353. https://doi.org/10.1136/ bmj.319.7221.1353 PMid:10567146 PMCid:PMC1117086

8. Kagan $\mathrm{SH}$, editor Ageism in cancer care. Seminars in Oncology Nursing; 2008: Elsevier. https://doi.org/10.1016/ j.soncn.2008.08.004 PMid:19000598

9. Hadbavna A, O'neill D. Ageism in interventional stroke studies. Journal of the American Geriatrics Society. 2013;61(11):2054-5. https://doi.org/10.1111/jgs.12537 PMid:24219215

10. Butler RN. Ageism: Another form of bigotry. The Gerontologist. 1969;9(1):243-6. https://doi.org/10.1093/ geront/9.4_Part_1.243 PMid:5366225

11. Levy SR. Toward reducing ageism: PEACE (positive education about aging and contact experiences) model. The Gerontologist. 2016;58(2):226-32. https://doi.org/ 10.1093/geront/gnw116 PMid:27510755

12. São José JMS, Amado CAF, Ilinca S, Buttigieg SC, Taghizadeh Larsson A. Ageism in health care: A systematic review of operational definitions and inductive conceptualizations. The Gerontologist. 2017;0(0):1-11.

13. Dobrowolska B, Jędrzejkiewicz B, Pilewska-Kozak A, Zarzycka D, Ślusarska B, Deluga A, et al. Age discrimination in healthcare institutions perceived by seniors and students. Nursing ethics. 2019;26(2):443-59. https://doi.org /10.1177/0969733017718392 PMid:28745574

14. Eymard AS, Douglas DH. Ageism among health care providers and interventions to improve their attitudes toward older adults: an integrative review. Journal of Gerontological Nursing. 2012;38(5):26-35. https://doi.org/ 10.3928/00989134-20120307-09 PMid:22420518

15. Institute of Medicine. Committee on the future health care workforce for older americans, Retooling for an aging America: Building the Health Care Workforce: National Academies Press; 2008.

16. Bonnie RJ, Wallace RB. Elder mistreatment: Abuse, neglect, and exploitation in an aging America: National Academies Press; 2003. 
17. Grove S, Burns N. The Practice of Nursing Research: Conduct, Critique, \& Utilization. Missouri: Elsevier Saunders; 2005.

18. Smedley BD, Stith AY, Nelson AR. Unequal treatment: Confronting racial and ethnic disparities in health care: National Academies Press; 2002.

19. Reza H. Ageism and indigenous elderly in Bangladesh: Concepts and its applicability. Journal of Ethnic Affairs. 2006;2:14-7.

20. Kagan SH, Melendez-Torres G. Ageism in nursing. Journal of Nursing Management. 2015;23(5):644-50. https://doi.org /10.1111/jonm.12191 PMid:24238082

21. Hausmann LR, Hannon MJ, Kresevic DM, Hanusa BH, Kwoh CK, Ibrahim SA. Impact of perceived discrimination in health care on patient-provider communication. Medical care. 2011;49(7):626. https://doi.org/10.1097/MLR. 0b013e318215d93c PMid:21478769 PMCid:PMC3117903

22. Crawley LM, Ahn DK, Winkleby MA. Perceived medical discrimination and cancer screening behaviors of racial and ethnic minority adults. Cancer Epidemiology and Prevention Biomarkers. 2008;17(8):1937-44. https://doi.org/10.1158/1055-9965.EPI-08-0005 PMid:18687583 PMCid:PMC2526181

23. Facione NC, Facione PA. Perceived prejudice in healthcare and women's health protective behavior. Nursing Research. 2007;56(3):175-84. https://doi.org/10.1097/ 01.NNR.0000270026.90359.4c PMid:17495573

24. Trivedi AN, Ayanian JZ. Perceived discrimination and use of preventive health services. Journal of general internal medicine. 2006;21(6):553-8. https://doi.org/10.1111/j.15251497.2006.00413.x PMid:16808735 PMCid:PMC1924636

25. Van Houtven $\mathrm{CH}$, Voils $\mathrm{Cl}$, Oddone EZ, Weinfurt $\mathrm{KP}$, Friedman JY, Schulman KA, et al. Perceived discrimination and reported delay of pharmacy prescriptions and medical tests. Journal of general internal medicine. 2005;20(7):57883. https://doi.org/10.1007/s11606-005-0104-6 PMid:16050850 PMCid:PMC1490147

26. Cameron S. A Study of Nurses' Attitudes Toward Medical Ageism. 2015.

27. Hsieh H-F, Shannon SE. Three approaches to qualitative content analysis. Qualitative health research. 2005;15(9):1277-88. https://doi.org/10.1177/10497323052 76687 PMid:16204405

28. Graneheim UH, Lundman B. Qualitative content analysis in nursing research: concepts, procedures and measures to achieve trustworthiness. Nurse education today. 2004;24(2):105-12. https://doi.org/10.1016/j.nedt.2003.10. 001 PMid:14769454
29. Guba EG. Criteria for assessing the trustworthiness of naturalistic inquiries. Ectj. 1981;29(2):75.

30. Iversen TN, Larsen L, Solem PE. A conceptual analysis of ageism. Nordic Psychology. 2009;61(3):4. https://doi.org/ 10.1027/1901-2276.61.3.4

31. de São José JMS, Amado CAF. On studying ageism in longterm care: a systematic review of the literature. International psychogeriatrics. 2017;29(3):373-87. https://doi.org/10.1017/S1041610216001915 PMid:27852342

32. Skirbekk H, Nortvedt P. Inadequate treatment for elderly patients: Professional norms and tight budgets could cause "ageism" in hospitals. Health Care Analysis. 2014;22(2):192$201 . \quad$ https://doi.org/10.1007/s10728-012-0207-2 PMid:22528026

33. Bodner E, Cohen-Fridel S, Yaretzky A. Sheltered housing or community dwelling: quality of life and ageism among elderly people. International psychogeriatrics. 2011;23(8):1197-204. https://doi.org/10.1017/S1041610211 001025 PMid:21729417

34. Ayalon L. Perceived age, gender, and racial/ethnic discrimination in Europe: results from the European social survey. Educational Gerontology. 2014;40(7):499-517. https://doi.org/10.1080/03601277.2013.845490

35. Levy B. Stereotype Embodiment: A Psychosocial Approach to Aging. Curr Dir Psychol Sci. 2009;18(6):332-6. https://doi.org/10.1111/j.1467-8721.2009.01662.x PMid:20802838 PMCid:PMC2927354

36. Levy BR, Zonderman AB, Slade MD, Ferrucci L. Memory shaped by age stereotypes over time. Journals of Gerontology: Series B. 2011;67(4):432-6. https://doi.org/10. 1093/geronb/gbr120 PMid:22056832 PMCid:PMC3391075

37. Meisner BA. Physicians' attitudes toward aging, the aged, and the provision of geriatric care: A systematic narrative review. Critical Public Health. 2012;22(1):61-72. https://doi.org/10.1080/09581596.2010.539592

38. Pekince $\mathrm{H}$, Aslan $\mathrm{H}$, Erci B, Akturk U. The attitudes of healthcare professionals in a state hospital towards ageism. Journal of Public Health-Heidelberg. 2018;26(1):109-17. https://doi.org/10.1007/s10389-0170849-5 